\title{
A New Record on the Morphometric Variations in the Populations of Horseshoe Crab (Carcinoscorpius rotundicauda Latreille) Obtained from Two Different Ecological Habitats of Peninsular Malaysia
}

\author{
T.C. Srijaya*, P.J. Pradeep, S. Mithun, A. Hassan, F. Shaharom and A. Chatterji \\ Institute of Tropical Aquaculture, University Malaysia Terengganu, 21030, Kuala Terengganu, Malaysia \\ *E-mail: sreejayamol@yahoo.com
}

Received: 05.05.2010, Accepted: 02.09.2010

\begin{abstract}
The allometric analysis was used to study the morphometric variability in two different populations of horseshoe crab (Carcinoscorpius rotundicauda, Latreille) collected from Setiu and Gelang Patah (Johor) of Peninsular Malaysia. Values of all parameters in male and female populations of Setiu were recorded high as compared to the horseshoe crab collected from Gelang Patah. In all relationships (total length, carapace length, carapace width and telson length) either with normal values or when values were converted into their logarithmic values, it showed a straight line which indicated that in both populations the increment of all body parts followed an isometric growth.
\end{abstract}

Key words: Carcinoscorpius rotundicauda, morphometric variations, Setiu, Gelang patah

\section{Introduction}

Morphometrics is an effective tool to study the variation and change in the form (size and shape) of organisms (Webster, 2007). Morphometric studies describe the quantitative measurement of different body parts specially useful for comparing different living organisms. A significant variation in the morphometric characteristics of animals belonging to the same population or genus has been reported by many workers (Chatterji, 1994). These variations in morphological structures help in studying the classification and identification of many species. The main morphological characteristics apparently look similar in all species and cannot be distinguished easily. But when data are analysed statistically of different populations inhabiting in several areas, a marked difference could be observed in their morphometric structures.

Allometric studies describe effectively the relationship between size and shape of an animal (Christopher, 1996). Analysis of allometric parameters in morphometric studies help in evaluating the differences of various body measurements of a species inhabiting in different ecosystems. It also provides important information regarding comparative growth 
of the various body parameter and relationship between differences in one body parameter to the other. The application of allometry was first described by Huxley and Tessier (1936) to calculate the population growth characteristics of many organisms. Since that time it has extensively been applied by many biologists to study the population diversity. Chatterji et al. (1988) suggested that the allometric relationship in horseshoe crab plays an important role in understanding the comparative morphometric variation in the population. It is a well known fact that the changes in the form of any body parts of an animal cannot be judged without using adequate allometric analysis. These parameters are however, useful in comparison of carapace or shell dimension of animals of known size within a locality which is a primary concern of such a study (Chatterji et al., 1988). The morphometric characters and their allometric relationships to a large extent are influenced by the age, local environmental conditions and population density of the species (Hickman, 1979; Schaefer et al., 1985; Chatterji et al., 1988). Additionally, the allometric relationship also provides important information regarding comparative growth of various body parameters of an individual. It is a well known fact that many aquatic animals change their body proportions even shape if they inhabit in different places. Phenotypic plasticity of an animal to a large extent is thus influenced by the environmental factors (Daniels et al., 1998).

In this study we have applied allometric relationship to study the morphometric variability in two populations of the horseshoe crab (C. rotundicauda) collected from Setiu and Gelang Patah (Johor) coastal areas on Peninsular Malaysia to establish the similarities and dissimilarities between these two populations of different habitats. The present study was also undertaken with an aim to examine how best the concept of allometry fitted to this species in describing morphometric diversity of $C$. rotundicauda populations in Peninsular Malaysia.

\section{Materials and methods \\ Study area}

Live specimens of the horseshoe crab $(C$. rotundicauda) migrating towards the shore for spawning, were collected along the eastern coast of Peninsular Malaysia at Setiu $\left(5^{\circ} 42^{\prime} 60^{\prime \prime} \mathrm{N}\right.$ and $\left.102^{\circ} 42^{\prime} 0^{\prime \prime} \mathrm{E}\right)$ and along the western coast at Gelang Patah (Johor) $\left(1^{\circ} 21^{\prime} 4^{\prime \prime} \mathrm{N}\right.$ and $\left.103^{\circ} 32^{\prime} 33^{\prime \prime} \mathrm{E}\right)$ (Fig. $1)$.

\section{Sample collection}

Samples were collected in two different seasons (November, 2008 and June, 2009) with the help of local fishermen using a gill net of $25 \mathrm{~m}$ long, $6 \mathrm{~m}$ wide with mesh size of $10 \mathrm{~mm}$. A total of 308 specimens of the horseshoe crabs ranging in size from 270 to $333 \mathrm{~mm}$ (males) and 241 to $389 \mathrm{~mm}$ (females) were collected from Setiu, whereas 318 specimens ranging in size 229 to $323 \mathrm{~mm}$ (males) and 280 to $352 \mathrm{~mm}$ (females) from Gelang Patah (Johor). Specimens were brought to the laboratory and kept in a Fibreglass Reinforced Plastics (FRP) tank of $5000 \mathrm{~L}$ capacity provided with continuous circulation of seawater. Immediately after transporting samples to 
the laboratory, different body measurements of all specimens were recorded to $0.1 \mathrm{~mm}$ accuracy with the help of a Vernier Callipers as described by Chatterji et al. (1988).

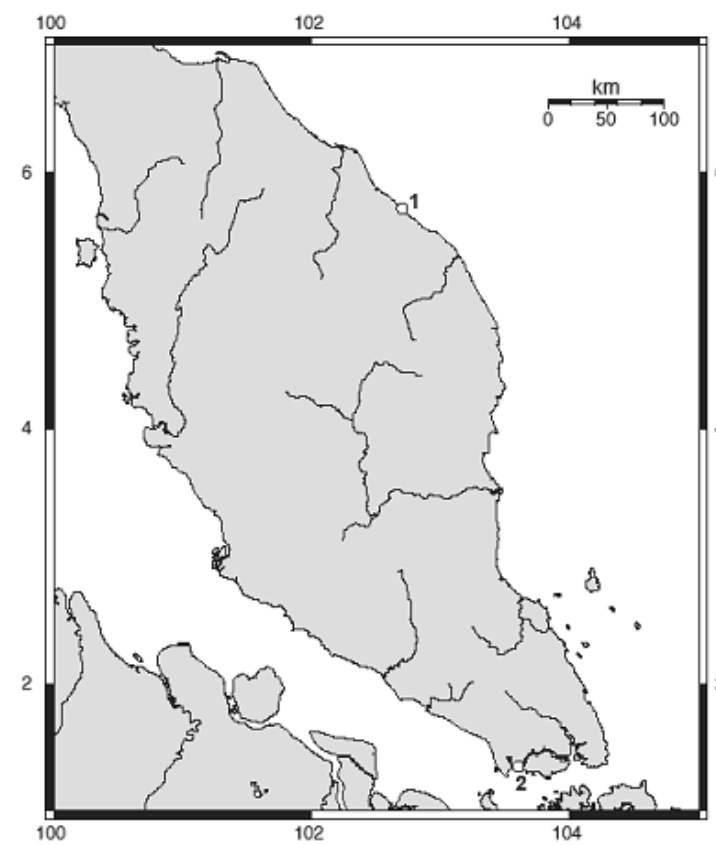

Figure 1. Locations of the sampling sites: Setiu (1) and Gelang Patah, Johor (2)

\section{Allometric analysis}

Data collected for all measurements were pooled according to the sex of specimens and place from where they were collected for the allometric analysis. The total length of each specimen was considered as a basis of references for all other measurements (Chatterji, 1976). The allometric analysis of all parameters were analysed following the method as described by Chatterji et al. (1988). A linear regression of various body measurements against total length was carried out by the least square method. Measurements of all characters were expressed as percent of the total length. Relationships of total length with different parameters were expressed using regression equation $(Y=a+b X)$ where ' $a$ ' and ' $b$ ' were considered as additive and multiplying constants. All values were again converted into their logarithimic form and equation $\log Y=a+b \log X$ was calculated separately for each group and a straight line was fitted to the scatter diagram using SPSS 11.5 version. To establish difference, if any, between the regressions of log total length of the horseshoe crab with different body parts of each group and correlation coefficient was employed to evaluate the significance level (Chatterji et al., 1988).

\section{Results}

The mean values of all measurements of males and females collected from two different environments are given in table 1. Measurements of all parameters in male and female populations of Setiu recorded high as compared to the horseshoe crab collected from Gelang Patah (Johor) (Fig. 2). In Setiu population of the horseshoe crab, the total lengths of males and females showed higher values of 9.30 and $1.98 \%$, respectively as compared to Gelang Patah (Johor) population (Tab. 2). Similarly, the carapace length, carapace width and telson length showed 2.65, 1.26 and $16.26 \%$ higher values in males of Setiu population as compared to male specimens collected from Gelang Patah (Johor). In female population of Setiu, the carapace length, carapace width and telson length were higher by 9.46 , 7.90 and $13.34 \%$, respectively as compared 
T.C. Srijaya, P.J. Pradeep, S. Mithun, A. Hassan, F. Shahoram and A. Chatterji /

Our Nature (2010) 8: 204-211

to the female population of Gelang Patah (Johor) (Fig. 4).

The regression analysis of different body measurements on total length of specimens of both environments with correlation coefficient is tabulated in table 3 . The relationship between total length and carapace width $(0.469 \pm 0.91)$ and total length and telson length $(0.557 \pm 0.90)$ were significant among males collected from Setiu. However, the relationship between total length and telson length was highly significant $(0.0639 \pm 0.96)$ in males of Johor. None of the relationship was found significant in specimens of female of both environments (Tab. 3). This showed that in the population of horseshoe crab of Setiu, the carapace width and telson length increased proportionately at par with total length in males whereas in Gelang Patah (Johor), the telson length only showed a proportionate increment. A detailed analysis of all body measurements of both populations were carried out by applying the regression equation (Tab. 3). In all relationships either with normal values or when values were converted into their logarithmic values, it showed a straight line which indicated that in both populations, the increment of all body parts followed an isometric growth. In males of Setiu population, the relationship between total length and carapace width was significant $\left(r^{2}=0.91\right)$ (Tab. 3). Similarly in males of the same population, the total length and telson length showed a significant relationship $\left(\mathrm{r}^{2}=\right.$ 0.90) (Tab. 3). However, in males collected from Gelang Patah (Johor), the total length and telson length relationship was found to be highly significant $\left(\mathrm{r}^{2}=0.96\right)$ (Tab. 3). In all relationships, the exponential constant values were $\sim 1$ indicating that the growth in all body parts of both populations followed an isometric growth pattern.

\section{Discussion}

Chatterji et al. (1988) observed while studying the length and weight relationship of $C$. rotundicauda that the application of allometrics in horseshoe crab population helped in understanding the comparative morphometric diversity of the species. This particular study also has given emphasis on collection of data from specimens of the horseshoe crab those were randomly collected from respective areas (Setiu and Johor) for the application of morphometric analysis. In the present study all specimens collected for morphometric study belonged to groups of brooders migrating towards two different coasts for spawning purposes. Chatterji et al. (1988) stated that the allometric relationship between carapace length and soft body parts provides a better understanding of the growth of a species. In the present study, the total length of the horseshoe crab was considered as a reference for comparing relationships with different body parts. Application of allometry clearly showed significant dissimilarities in the different body parts of the two populations from Setiu and Johor in the present study. Relationships between the total length-carapace length, total lengthcarapace width and total length-telson length were found linear as evident in the present study. These relationships suggest that all these three parameters constantly increased proportionately. This also confirms a uniform growth pattern of these 
T.C. Srijaya, P.J. Pradeep, S. Mithun, A. Hassan, F. Shahoram and A. Chatterji / Our Nature (2010) 8: 204-211

Table 1. Mean of the different body measurements with their standard deviation

\begin{tabular}{lcccc}
\hline \multirow{2}{*}{ Parameters (mm) } & \multicolumn{2}{c}{ Setiu } & \multicolumn{2}{c}{ Johor } \\
\cline { 2 - 5 } & Male & Females & Males & Females \\
\hline Total length & $306.9 \pm 6.41$ & $313.0 \pm 30.52$ & $277.3 \pm 16.89$ & $306.8 \pm 15.92$ \\
\hline Carapace length & $139.3 \pm 8.39$ & $169.1 \pm 5.47$ & $135.6 \pm 5.82$ & $153.1 \pm 10.23$ \\
\hline Carapace width & $150.0 \pm 8.03$ & $172.7 \pm 6.70$ & $148.1 \pm 6.58$ & $159.1 \pm 7.01$ \\
\hline Telson length & $177.7 \pm 9.64$ & $188.1 \pm 4.55$ & $148.8 \pm 10.96$ & $163.0 \pm 3.01$ \\
\hline
\end{tabular}

Table 2. Percent difference of various measurements of Setiu population with Gelang Patah (Johor) population

\begin{tabular}{lcc}
\hline Parameters $(\mathbf{m m})$ & \multicolumn{2}{c}{ \% difference of parameters } \\
\cline { 2 - 3 } & Males & Females \\
\hline Total length & 9.30 & 1.98 \\
Carapace length & 2.65 & 9.46 \\
Carapace width & 1.26 & 7.90 \\
Telson length & 16.26 & 13.34 \\
\hline
\end{tabular}

Table 3. Statistical analysis of different body measurements and their relationship with total length

\begin{tabular}{|c|c|c|c|c|c|c|}
\hline \multirow{2}{*}{ Parameters } & \multicolumn{3}{|c|}{ Setiu } & \multicolumn{3}{|c|}{ Johor } \\
\hline & $\mathrm{RC}(\mathrm{b})$ & $\mathrm{CC}\left(\mathrm{r}^{2}\right)$ & $\mathrm{S}$ & $\mathrm{RC}(\mathrm{b})$ & $\mathrm{CC}\left(\mathrm{r}^{2}\right)$ & $\mathrm{S}$ \\
\hline \multicolumn{7}{|l|}{$\overline{\text { Male }}$} \\
\hline TL:CL & 0.453 & 0.78 & NS & 0.299 & 0.75 & NS \\
\hline TL:CW & 0.469 & 0.91 & $\mathrm{~S}$ & 0.352 & 0.81 & NS \\
\hline TL:TEL & 0.557 & 0.90 & S & 0.639 & 0.96 & S \\
\hline \multicolumn{7}{|l|}{ Female } \\
\hline TL:CL & 0.105 & 0.34 & NS & 0.516 & & \\
\hline TL:CW & 0.121 & 0.30 & NS & 0.376 & 0.73 & NS \\
\hline TL:TEL & 0.080 & 0.10 & NS & 1.425 & 0.88 & NS \\
\hline
\end{tabular}

$\mathrm{RC}=$ Regression Coefficient, $\mathrm{CC}=$ Correlation Coefficient, $\mathrm{TL}=$ Total length, $\mathrm{CW}=$ Carapace width, $\mathrm{TEL}=$ Telson length, NS= Not significant, $\mathrm{S}=$ Significant.

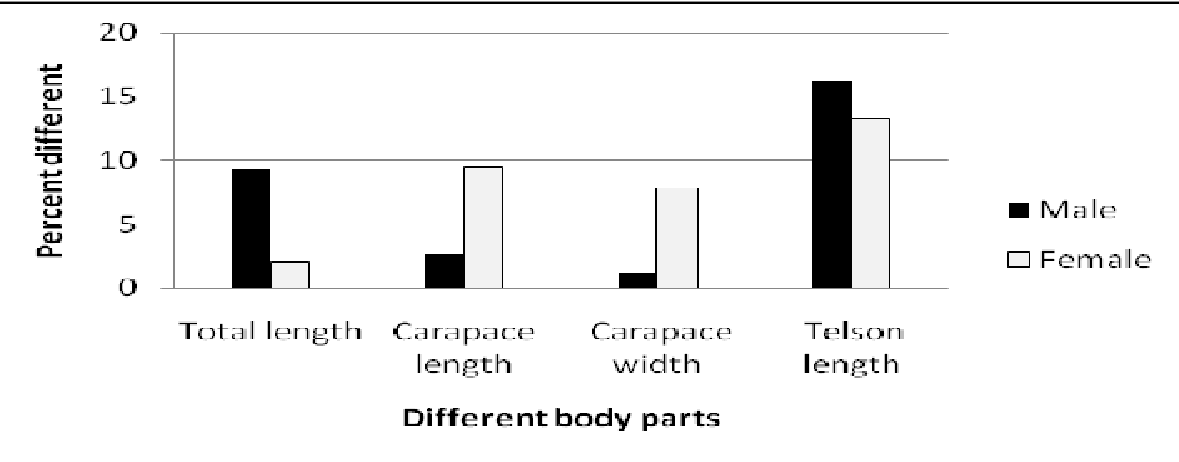

Figure 2. Percent difference of various parameters of Setiu population with Johor population. 
T.C. Srijaya, P.J. Pradeep, S. Mithun, A. Hassan, F. Shahoram and A. Chatterji / Our Nature (2010) 8: 204-211

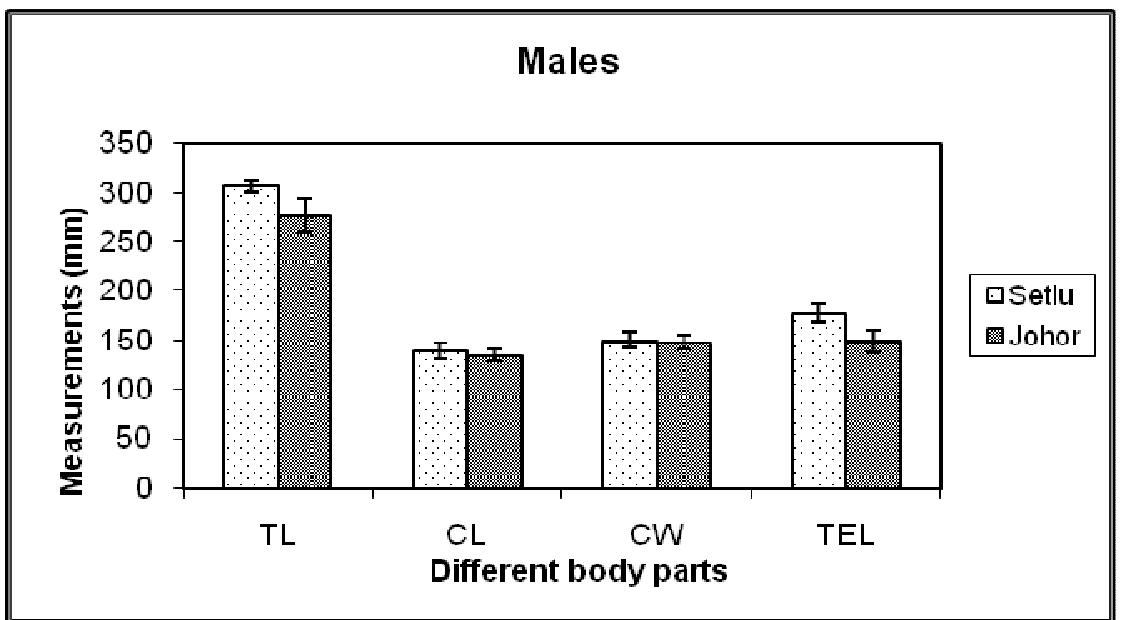

Figure 3. A comparison of different body parts in males collected from two environments. TL= Total length, $\mathrm{CW}=$ Carapace width, $\mathrm{TEL}=$ Telson length

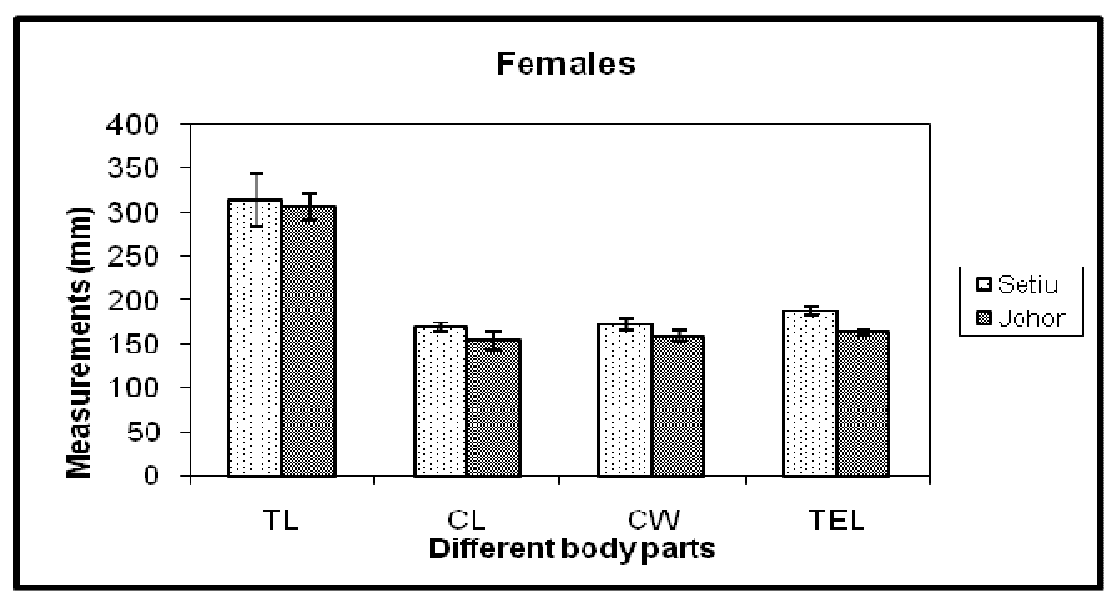

Figure 4. A comparison of different body parts in females collected from two environments. TL= Total length, $\mathrm{CW}=$ Carapace width, $\mathrm{TEL}=$ Telson length

three body dimensions with the much work has so far been done on the advancement of the growth of $C$. allometric relationship of horseshoe crab rotundicauda in both environments. collected from different environments.

It is surprising to note that except the preliminary work done by Chaterji et al. (1988) and Vijayakumar et al. (2000) not However, it has been reported that the ontogenetic changes in the relative growth of different parts of males and females of 
the spider crab (Maja squinado) are related to their maturity stages which helps in defining criteria to assign for each growth phase (Sampedro and Gurriaran-Gonzalez, 2004). The discontinuous growth of crustaceans also enables morphometric data to be used to separate sexually immature and mature animals. This is accomplished by noting any discontinuity to the size at which sexual maturity is attained (Wayne, 1990).

In the present study, the allometric relationships were almost linear in all parameters collected from two different habitats which showed that the growth in these parameters was isometric in both populations. However, in many aquatic animals, the ratio between different body parts with increasing total length does not show a constant relative growth (Chatterji, 1976). In the male population of Setiu, the total length and telson length increased more rapidly than the population of Gelang Patah (Johor). Similarly, in females of Setiu, the carapace length and telson length increased more rapidly than females of Gelang Patah (Johor). In both males and females populations of Setiu, a significant difference in these morphometric characters was observed which showed that though in both sexes, the allometric relationship was isometric but the pattern in growth increment was different in the both sexes.

In the present study, carapace width and body length relationship showed a proportionate increment. A significant relationship was observed between carapace length and carapace width of the horseshoe crab, C. rotundicauda by Chatterji et al. (1988) confirming the present observation.
The ratio of carapace width and total length in $T$. gigas has been reported to increase with the increase in the age of the horseshoe crab which suggested that as the animal grew older, they became wider and many times, values of carapace width exceeded than that of carapace length (Vijayakumar et al., 2000). The data analysed although during this study was not of a greater magnitude however, it is still possible to infer that the allometric relationship among various parts of the body is functionally important in the biology of the organism and particularly serve as a predictive tool for ecological investigations. Changes in the body dimensions of the $C$. rotundicauda populations from two different areas indicate that the relationship could indirectly be influenced by local environmental conditions effecting significantly on the growth of animals.

The significant difference in morphometric characters of the horseshoe crab between two different habitats strongly suggests that these specimens belong to two different independent stocks. The carapace widths in the population of Siam Gulf (Thailand), Bangladesh and Sunderbans areas of West Bengal in India were reported to be $119 \pm 0.7 ; 133 \pm 0.8$ and $150 \pm 0.7 \mathrm{~mm}$; respectively as compared to the Malaysian horseshoe crab population of Setiu $(161 \pm 6.70)$ and Gelang Patah $(153 \pm 7.01)$ as reported by Chatterji (1994). These differences in morphometric characters of C. rotundicauda of different environments might be due to environmental effects of the habitat or it might be related with genetic effect (Krumholz and Cavanah, 1968). The population of horseshoe crab reported so far 


\section{T.C. Srijaya, P.J. Pradeep, S. Mithun, A. Hassan, F. Shahoram and A. Chatterji /}

Our Nature (2010) 8: 204-211

are migrating for spawning along the eastern coasts in most of the countries. The deeper zone along the eastern part seems to be the natural habitat of the horseshoe which provides most suitable environmental conditions. Due to this, the growth in different body parts is normal in Setiu population. However, the environmental conditions along the western coast seem to be unsuitable as compared to the eastern coast of Malaysia that effected in some disturbances in normal physiological function causing slow growth rate of different body parts of $C$. rotundicauda. There could be other reasons also which need further detailed studies using appropriate molecular tools to find out the exact cause of differential growths in the body parts in these two populations of $C$. rotundicauda.

\section{Acknowledgements}

The authors are thankful to the Vice Chancellor, Prof. Dr. A. Deraman of University Malaysia Terengganu for providing hatchery and laboratory facilities. The authors are also grateful to the University Malaysia Terengganu for providing SKS fellowships to PJP, STC and Principal Research Fellowship to A. Chatterji.

\section{References}

Chatterji, A. 1976. Studies on the biology of some carps. Aligarh Muslim University, Aligarh. 122 p. (Ph.D. Thesis)

Chatterji, A. 1994. The Indian horseshoe crab-a living fossil. A Project Swarajya Publication. $157 \mathrm{p}$.
Chatterji, A., R. Viyayakumar and A.H. Parulekar 1988. Growth and morphometric characteristics of the horseshoe crab, Carcinoscorpius rotundicauda (Latreille) from Canning (West Bengal), India. Pak. J. Sci. Ind. Res. 31(5): 352-353.

Christopher, G.S. 1996. The statistical theory of shape. Springer. pp. 4.

Daniels, S.R., B.A. Stewart and M.J. Gibbons 1998. Genetic and morphometric variation in the potamonautid river crab, Potamonautes parvispina (Decapoda: Potamonautidae) from two Western Cape rivers, South Africa. $J$. Nat. Hist. 32 (8): 1245-1258.

Hickman, J.C. 1979. The basic biology of plant numbers. In Topics in plant population biology (Eds. O.T. Solbrig, S.K. Jain, G.B. Johnson and P.H. Raven). Columbia University Press, New York. pp. 232-263.

Huxley, J.S. and G. Tessier 1936. Terminology of relative growth. Nature 137: 780-781.

Krumholz, L.A. and H.S. Cavanah 1968. Comparative morphometry of freshwater drum from two Midwestern localities. Trans. Am. Fish. Soc. 97: 429-441.

Sampedro, M. and E. Gurriaran-Gonzalez 2004. Aggregating behaviour of the Spider Crab, Maja squinado in shallow waters. J. Crust. Biol. 24(1): 168-177.

Schaefer, R., K. Trutschler and H. Rumohr 1985. Biometric studies on the bivalves Astarte elliptica, A. borealis and A. montagui in Kiel bay (Weastern Baltic sea). Helgolander Meeresunters 39: 245-253.

Vijaykumar, R., S. Das, A. Chatterji and A.H. Parulekar 2000. Morphometric characteristics in the horseshoe crab, Tachypleus gigas (Arthropoda: Merostomata). Ind. J. Mar. Sci. 29: 333-335.

Wayne, B.D. 1990. Morphology via Orthography: a visual approach to oral decisions. Appl. Linguist. 11: 238-252.

Webster, M. 2007. A cambrian peak in morphological variation within trilobite species. Science 317(5837): 499-502. 